\title{
Perception of the World through the Prism of Culture
}

\author{
Narine Harutyunyan \\ Yerevan State University
}

$\mathrm{E}$ xisting objectively, the surrounding world is refracted in the human consciousness through the prism of culture, modified on the basis of a person's individual perceptions. Thus, the linguistic worldview includes universal features common to the whole humanity; cultural-specific features - "some kind of a cultural "core," common to all the members of the social group or community" (Leontyev 1997:273); as well as individual features inherent in a certain person.

The world is defined by a system of philosophic views, religious beliefs, cultural traditions, moral values, convictions, prejudices and stereotypes. A multitude of subjective factors influences the formation of the worldview: sharpness of the eyesight of the individual, his/her height, spirit of life, profundity of knowledge about the world etc..

In the process of cognition a human being creates conceptual models (the so-called "mental maps" of the world), presenting perceptive images of the surrounding reality in a simplified form. The nature of the worldview of the communicant depends on how universal culture-specific and personality components are balanced in it. From cross-cultural perspective, the worldview of a person who was born and has lived all his/her life in a small, distant village will significantly differ from that of an individual who is used to traveling around the world and has lived all his/her life in megapolis. At the same time, one may not claim that the latter will have advantages from the point of view of the profundity of knowledge about the world: an erudite who has lived all his/her life in one place may have an encyclopedic knowledge about the world as a whole and a profound knowledge about a specific fragment of reality.

The vision of the world/worldview is made up of joint insights obtained by means of different organs of sense perception, such as sounds, scents and smells, visual images etc. For example, smell is the most powerful sense for recalling our memories and arousing emotions. When we notice the smell of perfume, perhaps we remember the sweetest/the most bitter moments from our past, because smell evokes much deeper memories than either vision or sound. The power of smell to remind us of the past probably plays a part in people's emotional attachment to a local place and their childhood homes. If, as Ed. Hall claims, American society has few smells, then it is not surprising that Americans are more mobile than people in some other societies. "In the use of smell Americans are culturally underdeveloped. The extensive use of deodorants and the suppression of odor in public places results in a land of olfactory blandness and sameness that would be difficult to duplicate anywhere else in the world. .... Our cities lack both olfactory and visual variety. Anyone who has walked along the streets of almost any European village or town knows what is nearby. What smells do we have in the US that can compare to those in the typical French town where one may savor the smell of coffee, spices, vegetables, freshly plucked fowl, clean laundry and the characteristic odor of outdoor cafes? Olfaction of this type can provide a sense of life" 
( $<$ http://www.nicks.com.au/index.aspx?link_id=76.1389>).

On the stage preceding language embodiment, the vision of the world is characterized by vagueness and indefiniteness. Only when verbalized, subject series and relations between objects acquire vivid shapes and occupy their place in the system of human worldview.

The unity of the worldview predestines the existence of a universal semantic component of the language, whereas the idiosyncrasy of the culture of a specific nation adds an ethno-national specificity to it (Mechkovskaya 1996:51), thus conditioning the ethnopsycho-linguistic determination of the linguistic consciousness.

As a rule, when exploring the linguistic vision of the world, linguists first of all pay attention to the lexical fund of the language that stands out as the "upper level" of linguoculture. Lexical units are the surface layer of the language, the cultural specifics of which is the most obvious. However, they do not exhaust the whole set of means by which the national-cultural differentiation of linguistic worldviews is carried out. This explains why mastery of the lexical fund of a foreign language apart from culture does not usually lead to a cardinal transformation of the worldview: the communicant only applies foreign words to his/her own already existing view of reality.

"Having learnt a foreign word, a person as if extracts a piece of mosaic from a foreign, not completely familiar picture and tries to combine it with the worldview existing in his/her consciousness, programmed by his/her native language" (Ter-Minasova 2000:48). The inability to combine "jigsaw pieces" during cross-linguistic contacts, to visualize an object denoted by a word leads to incorrect reference and erroneous translations of cultural realia.

During cross-cultural contacts a clash of two worldviews takes place. A person appearing in an alien cultural-linguistic space brings with himself/herself an individual image of the world, which does not completely coincide with the linguistic worldview existing in the given linguoculture. The first thing that catches his/her eye are the realias not having any analogues in the native culture of the communicant, as for example: Belisha beacon ${ }^{l}$, wheel clamp or wheel boot ${ }^{2}$. The word denoting a realia of another culture will not evoke any associations in the consciousness of a person who has never seen the corresponding object. On the other hand, the object seen but not named will not take its place in the linguistic worldview of the personality either. But even if the object is correctly identified and named with the help of language, this is not enough for it to organically blend with the individual's worldview. The same objects in different cultures can take different shapes and/or perform different functions. So, for example, dogs are pets in some cultures and food in others. In some cultures, certain animals are considered sacred and certainly would not be eaten. The Hindu elephant-headed God Ganesh is accompanied by a rat whenever he travels. Rats, like cows, are deified in India. No Hindu worship is complete without an offering to Ganesh and his companion, the rat. Rats are fed and rarely killed in India. Perception interpretations can even be revealed in how cultures use food to reinforce and express identities. For example, in China, rice is the symbol of well-being and fertility, that is why leaving one's job is called "breaking one's rice bowl". 
The above is true both for animate nature and inanimate objects. For example, benches with dedications is an inseparable part of the worldview of an Englishman. Whenever you step in a park or a public square, you are guaranteed to find at least one wooden park bench dedicated to someone who had a history there. Hyde Park, for example, has hundreds of them, some dating only a few years, other a few decades. One can walking around and imagining all the stories behind the benches. In Armenia we can distinguish another realia: pulpulak - a public water fountain. They are a significant part of our culture. Pulpulaks were and are often used by people to appoint meetings and by couples as dating locations. Some pulpulaks are erected in memory of dead relatives. In drinking from a memorial pulpulak, passers by give their blessing to the person in memory of whom it is constructed. Each of them has their own faces and many cultural ties with their surroundings. If a person has never been to Yerevan, they will remain an abstraction for him/her.

Thus, observing the view of the world in its dynamics is an extremely difficult task that becomes many times more complicated when we talk about interaction of cultures. The most important condition of successful cross-cultural communication is perceptive readiness to accept differences and expand the vision of the world when the communicant comes across phenomena unfamiliar to him or different from his/her previous experience.

\section{Notes:}

1. A Belisha beacon is an amber-coloured globe lamp atop a tall black and white pole, marking pedestrian crossings of roads in the United Kingdom, Ireland and in other countries (e.g., Hong Kong, Malta) historically influenced by Britain. It was named after Leslie Hore-Belisha (1893-1957), the Minister of Transport who in 1934 added beacons to pedestrian crossings, marked by large metal studs in the road surface. These crossings were later painted in black and white stripes, thus are known as zebra crossings. Legally pedestrians have the right of way (over wheeled traffic) on such crossings. Belisha beacons provide additional visibility to zebra crossings for motorists, primarily at night. The flash commonly lasts one second in both on and off states. Some crossings are set so that each beacon flashes alternately to the other side, but they often fall out of synchronisation over time. Beacons with an outer ring of flashing amber LED lights, preferred for their brightness and low electricity consumption, are replacing traditional incandescent bulbs in many areas ( $<$ http://en.wikipedia.org $>$ ).

2. A wheel clamp, also known as wheel boot or Denver boot, is a device that is designed to prevent vehicles from being moved. In its most common form, it consists of a clamp that surrounds a vehicle wheel, designed to prevent removal of both itself and the wheel.

In the United States, these devices became known as a "Denver boot" after the city of Denver, Colorado was the first in the country to employ them, mostly to force the payment of outstanding parking tickets (<http://en.wikipedia.org $>$ ). 


\section{References:}

1. Hall, Ed. (1966) The Hidden Dimension. Garden City, NY: Doubleday.

2. Leontyev, A.A. (1997) Osnovy psixholingvistiki. M.: Smysl.

3. Mechkovskaya, N.B. (1996) Socialnaja lingvistika. M.: Aspect Press.

4. Ter-Minasova, S.G. (2000) Yasyk i mejkulturnaja kommunikatsia. M.: SLOVO.

5. <http://www.nicks.com.au/index.aspx?link_id=76.1389>

6. <http://en.wikipedia.org >

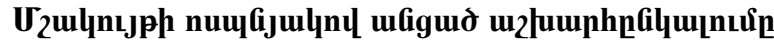

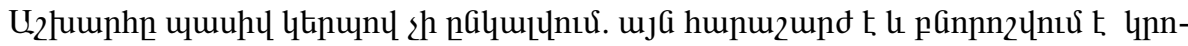

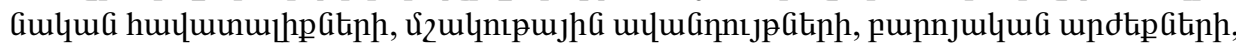

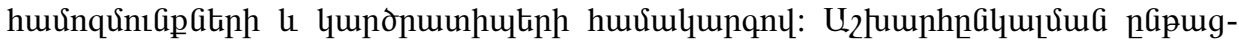

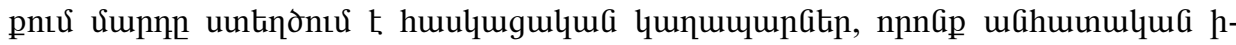

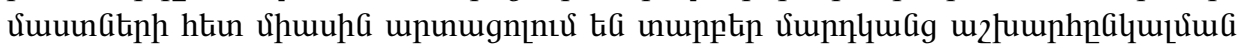

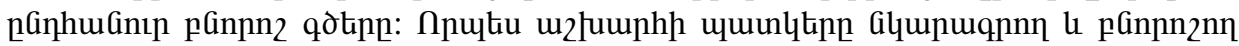

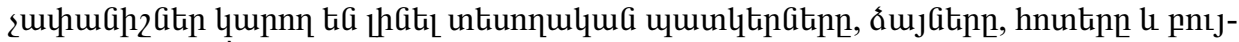

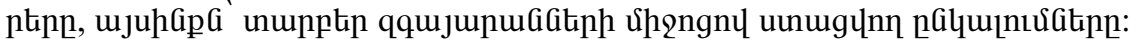

